\title{
Pengaruh Desain Interior Dalam Membangun Kepercayaan Klien di Kantor Notaris
}

\author{
Aditya Zaidan, Adivioe Candra, Elizabteh Phoebe, Lucretia Jessica \\ Interior Design Department, Fakultas Teknologi dan Desain, BINUS University \\ Jln. Araya Mansion No. 8-22, Pakis, Malang 65154 \\ aditya.falah@binus.ac.id, adivioe.panunggul@binus.ac.id, elizabeth,jeadi@binus.ac.id, \\ lucretia.jessica@binus.ac.id, andi.pramono.ac.id
}

\begin{abstract}
Abstrak
Notaris merupakan seseorang yang bekerja pada bidang jasa dan bertugas untuk membuat data otentik berdasar Undang-undang. membutuhkan tingkat kepercayaan yang tinggi dari klien agar mereka dapat bertahan didalam masyarakat. Kantor notaris sendiri akan menjadi tempat pertemuan seorang notaris dengan klien dan rekan kerja lainnya, yang secara tidak langsung dapat memberikan cerminan terhadap bagaimana kinerja dari jasa notaris tersebut. Teori menyebutkan bahwa kepercayaan juga dapat terbentuk dengan bantuan desain, desain yang baik pun juga dapat membentuk rasa aman dan nyaman pada diri seseorang yang berada di dalam ruangan tersebut. Penelitian ini bertujuan untuk memahami lebih dalam apakah sebuah desain interior dapat membantu meningkatkan kepercayaan klien pada notaris tersebut. Pengumpulan data penelitian dilakukan dengan menyebarkan angket kemudian dianalisis dan dibuat kesimpulan sebagai bahan dari penelitian. Dari penelitian dan pengumpulan teori yang telah dilakukan, dapat disimpulkan bahwa desain interior meliputi warna, tema, suasana, dan furniture yang digunakan pada sebuah kantor notaris, juga ikut berpengaruh terhadap tingkat kepercayaan klien kepada notaris yang bersangkutan.
\end{abstract}

Kata kunci: kantor, notaris, desain interior, kepercayaan, klien

\begin{abstract}
A notary is someone who works in the service sector and has the duty to create authentic data based on law. requires a high level of trust from clients so that they can survive in society. The notary office itself will be a meeting place for a notary with clients and other colleagues, which indirectly can provide a reflection of how the notary's services are performing. The theory states that trust can also be formed with the help of design, good design can also form a sense of security and comfort in someone who is in the room. This study aims to understand more deeply whether an interior design can help increase client confidence in the notary. Research data collection was carried out by distributing questionnaires then analyzed and conclusions were drawn as material from the study. From the research and theory collection that has been done, it can be concluded that the interior design includes the colors, themes, atmosphere, and furniture used in a notary's office, also influences the level of client trust in the notary concerned.
\end{abstract}

Keywords: notary, office, Interior design, trust, client

\section{Pendahuluan}

Dalam dunia bisnis, notaris merupakan usaha yang bergerak dalam bidang jasa yang tidak mudah persaingannya karena membutuhkan tingkat kepercayaan tinggi dari masyarakat untuk dapat bertahan. Tugas utama notaris sendiri adalah membuat data otentik yang berlandaskan 
Undang-Undang, dan ada pun yang merangkap sebagai Pejabat Pembuat Akta Tanah yang bertugas untuk membuat akta-akta otentik tentang perbuatan hukum atas tanah. Pertambahan jumlah notaris akan selalu bertambah setiap tahunnya karena kebutuhan izin dengan hukum terus berjalan dan tidak semua orang mempunyai wewenang untuk mengolah data atau akta dengan landasan hukum yang sah. Untuk menjadi unggul, sebuah organisasi harus mempunyai keunggulan kompetitf (Xenikou \& Simosi, 2006). Notaris dan karyawan yang kompeten dan teliti dalam melayani akan sangat dibutuhkan untuk bertahan dalam persaingan dengan mempertahankan kepercayaan klien.

Seperti dikatakan oleh (Goleman, D, Boyatzis, \& McKee, 2002), faktor internal seperti kepribadian dan perilaku pemilik bisnis, komitmen dan visi, pengetahuan, pengalaman, interaksi pribadi pemilik dengan pihak luar, kepemimpinan dan fleksibilitas dipercaya menjadi faktor penentu kesuksesan. Selain kepemimpinan dan jiwa kompeten, interaksi pribadi dengan pihak luar juga menjadi salah satu poin penting. Interaksi pribadi dengan pihak luar dapat dilakukan secara tidak langsung, maupun langsung di kantor milik notaris itu sendiri. Kantor tersebut akan menjadi tempat pertemuan seorang notaris dengan klien dan rekan kerja lainnya, yang secara tidak langsung akan memberi cerminan terhadap bagaimana kinerja dari jasa notaris tersebut. Dalam teori environmental behaviour, Mehrabian (Mehrabian \& Russell, 1974) menyatakan bahwa interaksi individu dengan lingkungan sekitar berupa elemen fisik menghasilkan perilaku yang dimediasi oleh tanggapan emosional individu. Elemen fisik tersebut dapat berupa sebuah interior kantor yang nantinya memberikan dampak emosional tertentu terhadap orang yang ada di dalamnya. Hal ini dapat digunakan oleh notaris untuk memberikan kesan terpercaya dan dapat diandalkan melalui interior kantornya. Kotler (Kotler, 1974) juga mengatakan bahwa faktor atmosfer sebuah ruang publik atau ruang komersial memiliki dampak terhadap perilaku konsumen.

Pada perancangan Pengaruh Desain Interior Dalam Membangun Kepercayaan Klien di Kantor Notaris, yang menjadi objek penelitian adalah Kantor Notaris dan PPAT Paulus Oliver Yoesoef S.H, yang merupakan salah satu kantor notaris di Kota Malang. Konsep yang digunakan untuk membangun kepercayaan klien adalah Warm and Modern. Kepercayaan yang terbentuk dalam desain akan menciptakan rasa aman dalam diri seseorang yang kemudian membawa kenyamanan untuk beraktivitas, sehingga akan timbul perasaan positif dalam pengalaman ruang tersebut (Caan, 2011). Di tengah kantor notaris yang terkesan serius dan memiliki kesibukkan yang tinggi, konsep ini akan memberikan kehangatan untuk orang di dalamnya agar merasa aman dan menurunkan kepenatan yang ada. Konsep modern yang dipilih ditujukan agar interior kantor tetap mengikuti zaman di tengah tren masa kini dan di tengah persaingan antar notaris yang semakin tinggi. Konsep Warm and Modern ini akan diaplikasikan pada ruang tunggu yang tentunya menjadi ruangan utama yang dituju saat berkunjung, ruang konsultasi atau ruang akad, ruang staff, dan ruang pribadi Notaris Paulus Oliver Yoesoef.

Menurut Berman dan Evans (Berman \& Evans, 1995), variable interior dari atmospheric variables yang relevan untuk perancangan ini meliputi skema warna, pencahayaan, dinding, lantai, plafon, furniture, dan unsur dekoratif. Konsep yang telah dipersiapkan tersebut akan menjadi pondasi dalam mendesain dan memilih variable interior agar suasana yang diinginkan dapat tercapai. Skema warna untuk keseluruhan lantai, dinding, plafon, dan furniture, serta pengaturan pencahayaan memilki peran penting untuk mencapai suasana hangat agar bisa dirasakan. Pemilihan furniture dan unsur dekoratif yang bertekstur dan bermode masa kini akan berperan penting dalam membentuk suasana modern pada Kantor Notaris dan PPAT Paulus Oliver Yoesoef S.H.

\section{Metode}

Penelitian yang dilakukan untuk mendapatkan pemecahan dari masalah desain interior yang dapat mempengaruhi kepercayaan klien terhadap notaris. Definisi penelitian adalah "suatu 
pendekatan untuk meneliti fenomena sosial melalui analisis kasus individual secara lengkap dan teliti, serta memberikan suatu analisis yang intensif dari banyak rincian khusus yang sering terlewatkan oleh metode penelitian lain" (Kumar, 1999). Penelitian yang akan dilakukan untuk jurnal ini adalah metode kualitatif kuantitatif.

Metode penelitian kualitatif adalah suatu riset yang bermaksud untuk memahami fenomena yang dialami oleh subjek penelitian. Contoh dari metode kualitatif adalah penelitian terhadap perilaku, persepsi, motivasi, dan tindakan yang dideskripsikan dengan kata-kata dan bahasa, dalam konteks alamiah (Moeloeng, 2005). Dalam metode ini, data-data merupakan rangkaian kata-kata dan bukan menggunakan angka untuk menunjukkan karakter dan pendapat responden mengenai topik terpilih. Sedangkan metode kuantitatif adalah perhitungan dan penganalisaan data responden yang menggunakan variable dengan perhitungan statistik. Penelitian kuantitatif adalah metode penelitian yang menggunakan proses data-data yang berupa angka sebagai alat menganalisis dan melakukan kajian penelitian, terutama mengenai apa yang sudah diteliti (Kasiram, 2008). Data berupa angket akan diambil sebagai data penelitian untuk keperluan analisis dan pengambilan kesimpulan untuk bahan penelitian jurnal ini.

\section{Pembahasan}

Berdasarkan survey yang telah dilakukan, terdapat 20 responden yang menjawab pertanyaan survey. Rata-rata responden mengetahui Kantor Notaris dan PPAT Paulus Oliver Yoesoef S.H dari rekan kerja maupun teman, dan beberapa ada yang menjawab karena pernah melewatinya. Responden percaya menggunakan Kantor Notaris dan PPAT Paulus Oliver Yoesoef S.H karena sudah mengenal bapak Paulus sendiri, dan beberapa menjawab karena branding kantor Kantor Notaris dan PPAT Paulus Oliver Yoesoef S.H sudah banyak dikenal di wilayah Malang. Kesan pertama dari responden saat melihat Kantor Notaris Paulus Oliver Yoesoef ada berbagai macam respon, ada yang bilang bagus dan besar, tetapi rata-rata menjawab tempatnya nyaman dan bersih. Saat ditanya mengenai kondisi visual interior Kantor Notaris Paulus Oliver Yoesoef mempengaruhi tingkat kepercayaan, rata-rata menjawab bahwa interior mempengaruhi tingkat kepercayaan, dikarenakan dapat menilai kinerja melalui tingkat profesional tempatnya, dan ada juga yang menjawab tidak karena itu tidak berpengaruh apapun terhadap kinerja karyawan sendiri. Responden diminta untuk menilai desain Kantor Notaris Paulus Oliver Yoesoef berdasarkan foto, 13 dari 19 responden menjawab terlihat nyaman, bagus,, bersih dan ada yang menjawab mewakilkan kewibawaan dari kantor tersebut. Rata rata dari responden menjawab jika dilihat dari virtual lokasi tersebut sangat nyaman dikarenakan suasana di kantor tersebut. Pertanayaan selanjutnya adalah bagaimana kenyamanan yang dirasa oleh responden ketika menunggu di Kantor Notaris Paulus Oliver Yoesoef, rata-rata menjawab terasa nyaman dikarenakan furniture dan ergonomi yang baik. Dan ada juga yang tidak menyukai furniturenya karena selera pribadi. Jawaban yang sama dengan pertanyaan ketika konsultasi. Ketika ditanya skala pengaruh desain terhadap tingkat kepercayaan rata-rata menjawab di angka 8, 10 dan sisanya 3-6, dengan alasan tempat yang nyaman dapat menunjang kinerja karyawan dan dapat mencerminkan kinerja karyawan. Dan pertanyaan sebaliknya, jika interior tidak baik, apakah responden tetap percaya terhadap Kantor Notaris Paulus Oliver Yoesoef, rata-rata menjawab tidak atau belum tentu dikarenakan responden berpikir bahwa kinerja tidak baik berdasarkan tempat yang terlihat tidak profesional.

Selain itu, pengamatan secara langsung juga dilakukan oleh penulis. Berdasarkan hasil pengamatan, Kantor Notaris Paulus Oliver Yoesoef berbeda dengan kantor notaris pada umumnya. Mayoritas kantor notaris menggunakan rumah pribadi yang dijadikan kantor sehingga terkadang tidak sesuai dengan fungsi bangunanya. Kantor Notaris Paulus Oliver Yoesoef sendiri sudah dibangun berdasarkan rancangan seorang desainer, sehingga desain keseluruhan bangunan dan interior sudah cukup nyaman dan sesuai untuk dijadikan kantor. Bangunan yang luas dan 
juga lokasi yang cukup nyaman membuat kantor ini menjadi salah satu kantor notaris ternyaman dan terbaik di Kota Malang.

Setiap bangunan pasti ada suatu masalah, dikarenakan Kantor Notaris Paulus Oliver Yoesoef sudah terkenal ke masyarakat, hal ini menjadikan klien yang berjumlah banyak. Kapasitas ruang tunggu tergolong sedikit dikarenakan pada peak day atau hari puncak, jumlah klien melebihi kapasitas yang ada sehingga banyak klien yang menunggu dengan berdiri dan juga ada klien yang melakukan akad pada tempat terbuka. Hal ini tentu mengurangi privasi masing-masing klien. Pencahayaan pada ruang tunggu sudah cukup dikarenakan dinding kaca yang memanfaatkan cahaya alami untuk menerangi ruangan. Tetapi pada ruang karyawan, penerangan buatan kurang terang. Hal ini disebabkan oleh jumlah lampu yang kurang dan intensitas cahaya yang kurang terang. Ditambah dengan wallpaper yang berwarna coklat dan krem membuat ruangan karyawan terkesan gelap.

Dari malasah-masalah tersebut, solusi yang dapat dilakukan adalah dengan menambah ruang tunggu, ruang konsultasi privat, resepsionis, dan menambahkan lampu serta menggati warna dasar keseluruhan ruangan menjadi lebih terang. Apabila klien merasa nyaman dan karyawan merasa nyaman juga, maka produktifitas dan keuntungan Kantor Notaris Paulus Oliver Yoesoef dapat meningkat.

\section{Hasil Desain}

Kantor Notaris Paulus Oliver merupakan salah satu kantor notaris terbaik di Kota Malang. Dengan kantor yang sudah terdesain dengan rapih dan modern tetapi masih terdapat beberapa masalah pada kantor tersebut diantaranya:

\section{- Existing}

Pada layout pada kondisi nyata atau existing, terlihat jika peletakkan furniture sudah cukup tepat. Namun saat melakukan survey secara langsung ditemukan beberapa hal yang tidak cocok. Seperti pada ruang tunggu ada meja resepsionis yang tidak dipakai sehingga memakan tempat. Lalu pada ruang staff cukup padat sehingga sirkulasi terasa sangat sempit. Serta akibat banyaknya dokumen hingga menumpuk memenuhi ruang staff sehingga kesannya sempit dan sesak.

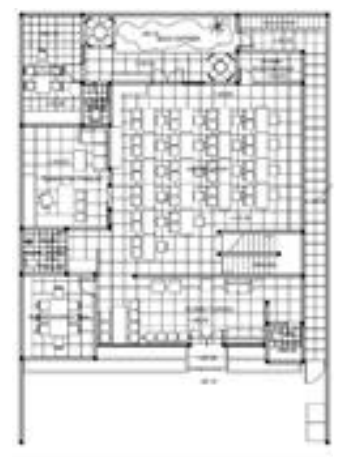

Gambar 1 Layout Existing Kantor Notaris Paulus Oliver (Sumber: Zaidan dkk, 2020) 


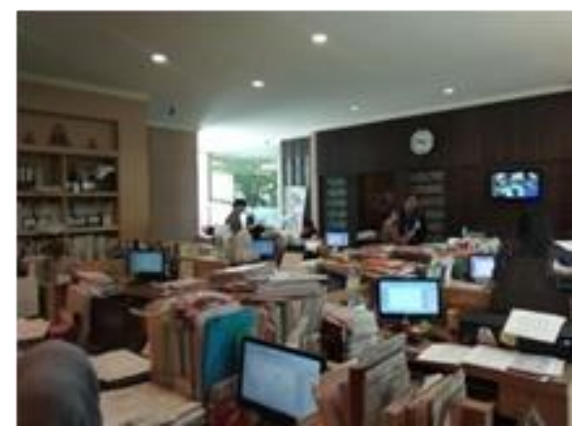

Gambar 2 Suasana Ruang Staff Kantor Notaris Paulus Oliver (Sumber: Zaidan dkk, 2020)

Dengan permasalahan tersebut maka dibuat layout baru dengan mengutamakan sirkulasi dan juga aspek ergonomic. Perubahan banyak terjadi pada area ruang tunggu, ruang staff, kan ruang pak Paulus sendiri.

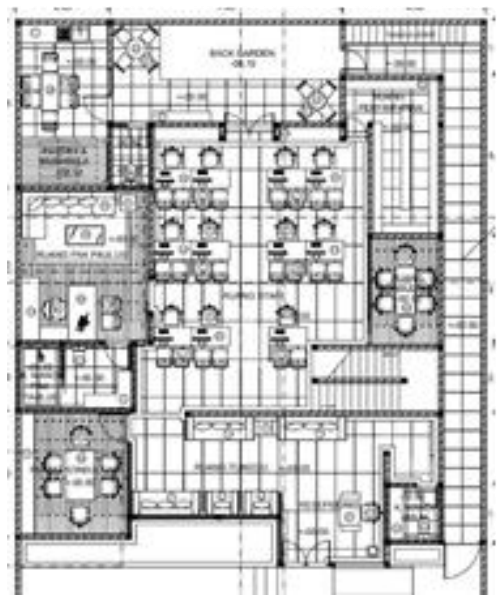

Gambar 3 Layout Redesign Kantor Notaris Paulus Oliver

(Sumber: Zaidan dkk, 2020)

- Ruang Tunggu dan Ruang Resepsionis

Dengan menambahkan ruang resepsionis, maka diharapkan dapat memudahkan klien saat datang ke Kantor Notaris Paulus Oliver. Ruang Resepsionis dibuat dengan konsep warm and modern. Untuk mencapai konsep tersebut, maka digunakan elemen kayu untuk meningkatkan konsep warm. Lalu warna menggunakan warna netral sehingga tidak terlalu mencolok dan bertolakbelakang dengan konsep yang diusung. Skema warna yang digunakan berupa monokromatik sehingga warna dapat bersatu dengan baik. Bentuk serta garis-garis dibuat lurus sehingga memberi kesan yang simple dan modern. Pada plafon diberi Ceiling lamp sebagai point of interest pada ruangan ini. 


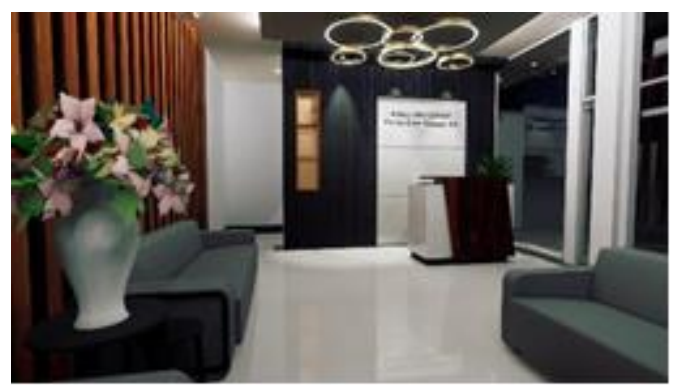

Gambar 4 Redesain Ruang Resepsionis (Sumber: Zaidan dkk, 2020)

Ruang tunggu di ubah dengan mengganti kursi besi dengan sofa. Ruangan ini menggunakan full sofa sebagai komoditas untuk klien duduk saat menunggu di Kantor Notaris Paulus Oliver. Dikarenakan ruang tunggu dan ruang resepsionis berdekatan, maka skema warna dibuat sesuai dan sama. Pada ruangan tunggu menggunakan elemen kayu sebagai dinding serta dibuat garisgaris vertical untuk memberikan kesan yang luas dan tinggi. Ditambahkan juga tanaman hias untuk menghidupi ruangan.

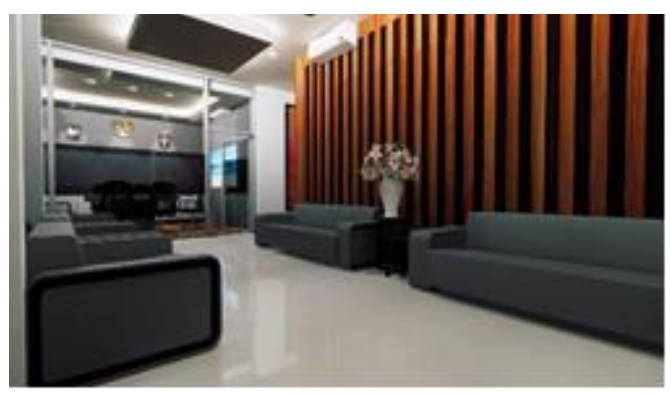

Gambar 5 Redesain Ruang Tunggu Klien (Sumber: Zaidan dkk, 2020)

\section{- Ruang Staff}

Ruang staff diubah layout arah meja para staff. Pada existing, layout meja menghadap ruang pak Paulus, tetapi pada hasil redesign, meja menghapad pintu masuk. Pada tengah-tengah meja diberi jalan agar memudahkan klien saat menuju meja salah satu staff. Agar meningkatkan sirkulasi, sebagian staff dipindahkan ke lantai atas sehingga yang dibawah memiliki ruangan yang cukup. Penambahan ruang berkas dan juga ruang konsultasi agar berkas tidak menumpuk di meja masing-masing staff dan ruang konsultasi menjadi 2 ruang yang dimana pada awalnya hanya memiliki 1 ruang. Skema warna yang digunakan pada ruang staff yaitu monokromatik dengan dominasi warna putih untuk meningkatkan konsentrasi para staff. Agar ruangan tidak terkesan monoton yang kosong, diberi backdrop dengan motif kayu. Backdrop ini juga berfungsi sebagai tempat penyimpanan berkas dan juga tempat print dan fotokopi. Pada plafon diberi drop ceiling dan indirect light untuk meningkatkan kesan warm and modern. 


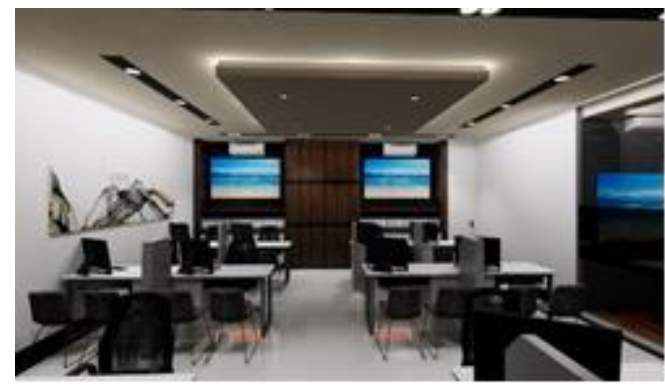

Gambar 6 Redesain Ruang Staff

(Sumber: Zaidan dkk, 2020)

\section{- Ruang Konsultasi}

Terdapat ruang konsultasi yang dapat menampung hingga 6 orang. Pada ruangan ini dapat dilakukan prosesi akad sehingga privasi klien tetap terjaga dengan baik. Untuk meningkatkan privasi klien, kaca pada ruangan konsultasi diberi efek buram atau sandblast agar tidak tembus pandang. Lalu peredam suara juga terpasang pada salah satu sisi tembok untuk meredam suara dari dalam keluar dan suara dari luar masuk ke dalam. Terdapat cabinet untuk menyimpan beberapa dokumen dan juga terdapat satu TV yang dapat dihubungkan ke perangkat pintar untuk presentasi dan lain-lain. Mayoritas ruangan menggunakan skema warna monokromatik sehingga tidak ada yang terlalu mencolok.

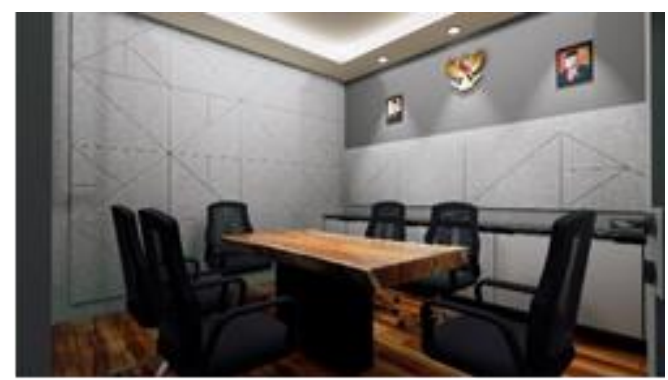

Gambar 7 Redesain Ruang Konsultasi (Sumber: Zaidan dkk, 2020)

\section{- Ruang Pak Paulus}

Ruang pak Paulus dibuat senyaman mungkin dan welcoming. Dengan skema warna monokromatik dan didominasi oleh warna abu-abu sehingga berbeda dengan ruang staff. Terdapat sofa untuk menyambut tamu khusus pak Paulus. Lantai diganti menggunakan vinyl motif kayu sehingga meningkatkan kesan hangat saat berada di dalam ruangan. Dipilih material berupa vinyl disebabkan oleh bahannya yang anti air dan mudah untuk melakukan perawatan. Terdapat lemari dan cabinet untuk memajang pajangan pribadi pak Paulus. 


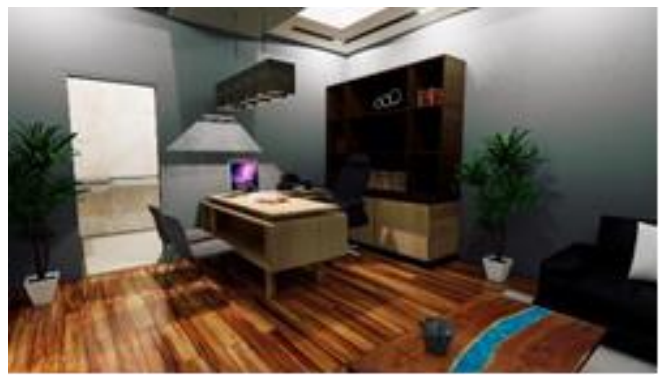

Gambar 8 Redesain Ruang Pak Paulus (Sumber: Zaidan dkk, 2020)

- Taman

Tidak banyak perubahan pada ruang belakang. Penataan ulang taman belakang dulakukan agar taman terkesan lebuh hidup. Lalu posisi dapur dan mushola diubah serta menambahan mahrab pada mushola. Warna keseluruhan di buat putih agar terkesan bersih dan netral. Pada bagian dapur dibuat minimalis dikarenakan minimnya staff menggunakan kompor untuk memasak. Disediakan kompor untuk memasak ringan seperti merebus air dan lain-lain. Terdapat loker khusus untuk staff menampung barang pribadi.

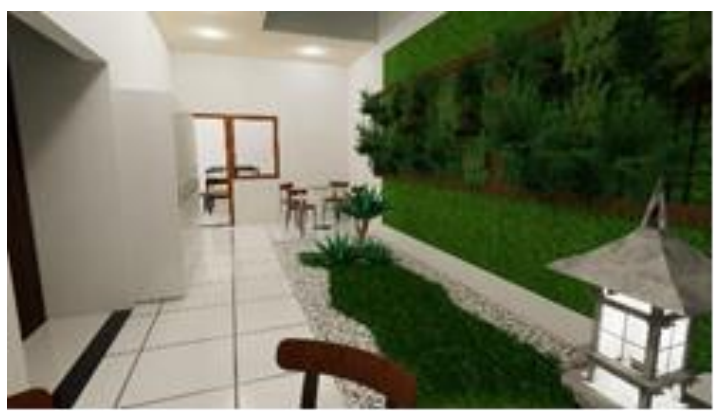

Gambar 9 Redesain Taman Belakang (Sumber: Zaidan dkk, 2020)

\section{MATERIAL}

Pemilihan material merupakan salah satu aspek terpenting dalam desain interior. Material yang dipilih berdasarkan kebutuhan desain dimana setiap material memiliki karakteristik tersendiri. Memilih material alami maupun sintetis memiliki keunggulan dan kekurangan masing-masing, berikut beberapa material yang digunakan dalam redesain Kantor Notaris Paulus Oliver :

\section{- Kusen Kaca}

Ada berbagai macam bahan untuk kusen, kayu dan aluminum lazim digunakan untuk kusen. Namun sekarang ada terobosan baru yaitu UPVC. Berbahan dasar PVC, UPVC memiliki keunggulan yaitu anti karat dan anti rayap. Bahan ini juga kuat dan tidak mudah untuk memuai. UPVC merupakan salah satu produk pengembangan dari Kusen PVC. Kusen PVC biasanya digunakan hanya sebagai material indoor karena PVC kurang kuat dan mudah patah. Namun berbeda halnya dengan UPVC. Material yang merupakan singakatan dari Unplasticized Poly Vynil Chloride adalah suatu material turunan plastik, yang sifat plastiknya diminimalisasi sehingga bentuknya menjadi keras (berkurang kelenturannya). Bagian dalam kusen UPVC diberi rangka sehingga kusen ini lebih kokoh dan berat. Rangka tersebut terbuat dari baja, namun ada 
pula yang dari besi galvanis. Perbedaan rangka inilah yang menyebabkan harga UPVC berbedabeda. UPVC yang berprofil baja tentu harganya lebih mahal bila dibandingkan dengan yang menggunakan besi galvanis. Dari segi kekuatan sulit membandingkan antara Kusen Alumunium dan Kusen UPVC. Sebab masing-masing antirayap, tahan terhadap air dan cuaca, dan minim perawatan. Walaupun terbuat dari logam, Kusen Alumunium yang kualitasnya baik tahan juga terhadap korosi. Begitupun UPVC karena terbuat dari turunan plasstik ia jelas bebas korosi. Cukup sulit untuk membandingkan antara kusen Aluminium dan kusen UPVC. Namun sebagai catatan, bahwa sambungan sudut Aluminium kebanyakan hanya menggunakan sekrup sehingga mudah lepas dan memuai. Akibatnya kaca yang dipegang kusen tersebut mudah terlepas. Walaupun tidak jarang dari sambungan ini air dapat merembes masuk. Sementara itu, UPVC disambung langsung di pabrik dengan menggunakan teknik pembakaran/pemanasan sehingga lebih kuat dan lebih tahan bocor. Kusen yang terbuat dari plastik UPVC yang dilapisi dengan bahan fire retardant yang bisa memperlambat laju api. (Sumber Gunung Kencana Cahaya Abadi, 2020)

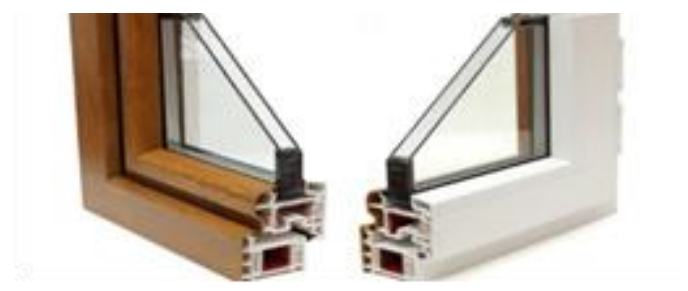

Gambar 10 Cross Section Kusen UPVC

(Sumber: https://kusen.co.id/jual-kusen-upvc-serat-kayu-bekasi/ diakses pada 1 Juli 2020)

- Kaca Jendela dan pembatas ruangan

Kaca adalah material padat yang merupakan zat cair yang sangat dingin karena molekulmolekulnya tersusun seperti air, namun kohesinya membuat bentuknya menjadi stabil. Hal ini terjadi karena proses pendinginan yang sangat cepat. Ini juga yang membuat kaca menjadi transparan atau tembus pandang. Kaca adalah amorf (non kristalin) material padat yang bening dan transparan (tembus pandang), biasanya juga rapuh atau mudah pecah. (Shabrina Alfari, 2020) Pemilihan tempered glass menjadi pilihan yang tepat, selain dari segi ketahanan, segi keselamatan kaca ini juga cukupbaik. kaca tempered merupakan jenis kaca yang memiliki kekuatan yang sangat tinggi, dibandingkan dengan kaca biasa. Dengan ketebalan yang sama, kekuatan kaca ini mampu mencapai 3-5 kali lipat dari kekuatan kaca biasa. Kaca ini tahan terhadap beban angin, tekanan air, benturan, dan perubahan temperatur yang tinggi (thermal shock). Kaca tempered juga lebih aman karena akan menjadi butiran halus bila pecah. Tempered glass merupakan kaca yang dikerasi dan apabila pecah, maka tempered glass akan pecah menjadi kepingan kecil yang tidak tajam dan berbahaya. Perancangan ini menggunakan tebal kaca dengan variasi 10-20 mm. 


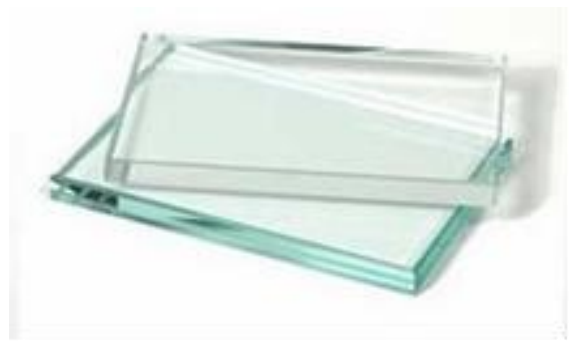

Gambar 11 Kaca Tempered

(Sumber: https://www.rumahmaterial.com/2014/04/mengenal-material-kaca- tempered.html diakses pada 1 Juli 2020)

\section{- Bahan Backdrop}

Backdrop menggunakan multipleks atau plywood ukuran $18 \mathrm{~mm}$. Secara bahasa Plywood berarti kayu lapis. Sedangkan menurut istilah plywood atau sering disebut Tripleks atau Multipleks adalah sejenis papan pabrikan yang terdiri dari lapisan kayu (Veneer) yang direkatkan bersamasama dengan menggunakan lem (glue). Plywood sering digunakan sebagai alternatif bahan bangunan yang dinilai ekonomis dan juga tahan terhadap lekukan dan perubahan cuaca. Biasanya daerah dengan iklim tropis menggunakan Plywood sebagai material bangunan, karena lebih tahan terhadap perubahan cuaca dan gempa. Selain ekonomis dan tahan terhadap perubahan cuaca, bahan ini juga mudah untuk diaplikasikan dan tidak membutuhkan keahlian khusus dalam menggunakannya. Dalam satu plywood itu terdiri dari beberapa jenis veneer yang disusun zig-zag, kemudian direkatkan. Veneer-veneer tersebut terdiri dari Face veneer, Short Core Veneer, Long Core Veneer, dan Back veneer. (Firman Hidayat, 2019) Multipleks merupakan plywood atau kayu lapis terbaik. Dengan beberapa lapisan triplek, menjadikan multipleks alternative lain. Multipleks dipilih sebab lebih tahan lama dibandingkan dengan blockboard dan particle board. Dilapisi dengan HPL untuk melindungi dari air apabila terjadi hal yang tidak diinginkan.

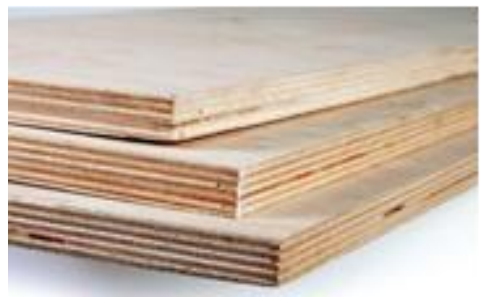

Gambar 12 Plywood multipleks dengan tebal variasi

(Sumber: . https://www.mebelkayukita.com/2017/11/apa-itu-mdf-hdf-hpl-multipleks-dan.html diakses pada 1 Juli 2020)

\section{Simpulan}

Berdasarkan hasil penelitian dan pembahasan yang telah kami bahas sebelumnya, maka kami dapat menyimpulkan beberapa hal seperti berikut :

1. Klien Kantor Notaris Paulus Oliver Yoesoef merasa bahwa desain yang berwarna warm sehingga memberi kesan serius dalam membangun image kantor notaris. Dalam Kantor 
Notaris dan PPAT Paulus Oliver Yoeseof S.H sudah menerapkan warna dan tema interior yang sesuai untuk sebuah kantor notaris.

2. Klien Kantor Notaris Paulus Oliver Yoeseof merasa ambience yang ada di kantor pun berpengaruh dalam mempercayakan seorang notaris. Pada Kantor Notaris dan PPAT Paulus Oliver Yoeseof S.H, klien merasa ambience yang ada sudah sesuai untuk sebuah kantor notaris, bahkan sudah cukup nyaman dengan menyediakan makanan dan minuman pada ruang tunggu.

3. Klien Kantor Notaris Paulus Oliver Yoeseof menganggap peletakan furniture juga berpengaruh penting dalam mereka memilih seorang notaris, baik dalam ergonomi dan pemilihan warna dalam furniture. Dan pada kantor tersebut ergonomi serta peletakan furniture sudah baik.

\section{Daftar Pustaka}

Berman, B., \& Evans, J. R. (1995). Retail Management: A Strategic Approach (6th ed.). Englewood Cliffs NJ: Prentice-Hall Inc.

Caan, S. (2011). Rethinking Design and Interiors: Human Beings in the Built Environment. China: Laurence.

Firman Hidayat. (2019). firman-inside.com. Diambil kembali dari https://www.firmaninside.id/2017/01/pengertian-plywood-dan-pembagian-grade.html

Goleman, D, D., Boyatzis, R., \& McKee, A. (2002). Primal leadership learning to lead with emotional intelligence. Boston Massachusetts: Harvard business Press.

Kasiram, M. (2008). Metodologi Penelitian. Malang: UIN-Malang Pers.

Kotler, P. (1974). Atmospherics as a Marketing Tool. Journal of Retailing, Vol 4 pp. 4865.

Kumar, R. (1999). Research Methodology. A Step-by-step Guide for Beginners. New Delhi: SAGE Publication.

Mehrabian, A., \& Russell, J. A. (1974). An Approach to Enviromental Psychology. Cambridge UK: MIT Press.

Moeloeng, L. (2005). Metologi Penelitian Kualitatif. Bandung: PT Remaja Rosdakarya.

Shabrina Alfari. (2020). arsitag.com. Diambil kembali dari https://www.arsitag.com/article/kacasebagai-bahan-bangunan

Sumber Gunung Kencana Cahaya Abadi. (2020). sgcka.co.id. Diambil kembali dari https://sgcka.co.id/dnews/10002/keunggulan-menggunakan-jendela-dan-pintu-daribahan-upvc.html

Xenikou, A., \& Simosi, M. (2006). Organizational culture and transformational leadership as predictors of bunisess unit performance. Journal of Managerial Psychology, Vol 21 No. $6: 566-579$. 
Lintas Ruang: Jurnal Pengetahuan \& Perancangan Desain Interior| Vol.7, No. 2, Th. 2019| Hal. 39 - 49 